\title{
High skies and oceans deep: polarity benefits or mental simulation?
}

\section{Daniël Lakens*}

School of Innovation Sciences, Eindhoven University of Technology, Eindhoven, Netherlands

*Correspondence: d.lakens@tue.nl

\section{A commentary on}

Congruency between word position and meaning is caused by task-induced spatial attention

by Pecher, D., Van Dantzig, S., Boot, I., Zanolie, K., and Huber, D. E. (2010). Front. Psychol. 1:30. doi: 10.3389/fpsyg.2010.00030

Pecher et al. (2010) presented targets (e.g., helicopter, submarine) $u p$ and down on a computer screen. Participants were either asked to indicate whether these objects were typically found in the ocean, or typically found in the sky. The authors examined whether congruency effects between the vertical position of words and their meaning were best accounted for by mental simulations or by polarity benefits (default asymmetries in the way people process dimensions). I believe their conclusion that polarity benefits cannot account for the interaction in reaction times between the meaning and the position of words is at best premature. Moreover, instead of explaining language understanding in terms of either simulation processes or linguistic input, a more fruitful approach might be to examine when meaning emerges from simulation processes, and when meaning is extracted from linguistic information (see Louwerse and Jeuniaux, 2010).

Pecher and colleagues state that "Certain dimensions are always coded in the same way." (p. 2). Although it is true that people are by default faster to process above relationships compared to below relationships (Clark, 1969), studies have shown that this default processing benefit can easily be reversed, depending on the nature of the task and characteristics of the stimuli. For example, Banks et al. (1975) asked participants to indicate which of two dots was located above (vs. below) the other. These dots were referred to as balloons, or as yo-yos. Participants were faster to indicate which of the two dots was the higher balloon, whereas they were faster to judge which of the two dots was the lower yo-yo. The crossover pattern observed in this study supports the idea that the default polarity codes of up as + polar and down as - polar can be reversed by framing the task in a different way. Proctor and Cho (2006, p. 428) similarly conclude: "In two-choice tasks with orthogonal stimulus and response sets, the responses are coded relative to multiple frames of reference."

A similar reframing occurs in the study performed by Pecher and colleagues. When thinking of skies, as in thinking of balloons, high skies are the default. Therefore, up becomes the default endpoint of the vertical dimension, and words presented up on the screen are responded to more quickly. When thinking of oceans, as when thinking of yoyos, the deep ocean is the default. Therefore, down becomes the default endpoint of the vertical dimension, and words presented down on the screen are responded to more quickly. This means that the interaction between task and position reported by Pecher and colleagues is an a priori prediction of (and not evidence against) a polarity explanation.

The second polarity effect Pecher and colleagues investigate is based on the assumption that right-hand key-presses receive a reaction time benefit because right is + polar. This prediction does not immediately follow from previous theoretical or empirical work. One study has revealed that responses are faster for arrows pointing toward the right than to the left, but importantly, these effects are eliminated when arrows are substituted by words (Olson and Laxar, 1973), and seem to be limited to explicit spatial categorizations where right key-presses are mapped onto stimuli presented up on the screen (Weeks and Proctor, 1990; Cho and Proctor, 2002). Furthermore, several researchers explicitly note that left-to-right space is symmetric, and should by default not reveal polarity differences (Clark, 1973; Seymour, 1974; Làdavas, 1988). Reaction time benefits for right key-presses are not ubiquitous in the literature, nor is such a main effect present in the study performed by Pecher and colleagues. Therefore, it is doubtful whether right key-presses should be coded as + polar.

Overall, the results of Pecher and colleagues provide little evidence against a polarity explanation for congruency effects between word meaning and vertical position. Given that previous studies that have investigated the vertical representation of concepts often show that +polar words (e.g., powerful, moral) are categorized faster than -polar words (i.e., powerless, immoral), and words presented up are categorized faster than words presented down, it seems premature to exclude polarity effects from influencing categorization times(e.g., Schubert, 2005; Meier et al., 2007). Indeed, as predicted by the polarity correspondence principle (Proctor and Cho, 2006), these experiments typically do not reveal differences in the categorization times for - polar words presented up or down. At the same time, studies have revealed that words can direct attention upward or downward (Richardson et al., 2003; Bergen et al., 2007; Van Dantzig, 2009). Instead of attributing effects to either simulation processes or polarity effects, several researchers have recently proposed models of conceptual processing that rely on both semantic and embodied information (Barsalou et al., 2008; Andrews et al., 2009; Louwerse, in press).

Such an interplay between linguistic and embodied sources of meaning might be able to provide a more integrative model of conceptual thought, especially for more abstract concepts. As an example, consider Lakoff and Johnson's (1980) Conceptual Metaphor Theory which describes how abstract concepts (e.g., power, valence, morality) are mapped onto concrete dimensions (e.g., verticality, size, brightness). These mappings are argued to result from experiential co-occurrence of 
the abstract and concrete domains, such as drooped postures when we feel down. This reasoning cannot explain the fact that practically all conceptual metaphors map abstract + polar concepts onto concrete + polar endpoints of dimensions (e.g., happy = up, warmth = affection, powerful = large) and vice versa (see Krzeszowski, 1997). Perhaps linguistic structures such as polarity differences constrain the specific mappings that emerge between abstract and concrete dimensions, thereby shaping how concepts are grounded.

Activated word associations, statistical regularities in language, and linguistic structures can guide simulation processes (for examples, see Barsalou et al., 2008; Louwerse and Jeuniaux, 2010), and should be taken into account when aiming to explain language comprehension. Linguistic and concrete information both contribute to conceptual thought; the challenge for future research lies in specifying how meaning emerges from their dynamic interaction.

\section{REFERENCES}

Andrews, M., Vigliocco, G., and Vinson, D. P. (2009). Integrating experiential and distributional data to learn semantic representations. Psychol. Rev. 116, 463-498.

Banks, W. P., Clark, H. H., and Lucy, P. (1975). The locus of the semantic congruity effect in comparative judgments. J. Exp. Psychol. Hum. Percept. Perform. 104, 35-47.
Barsalou, L. W., Santos, A., Simmons, W. K., and Wilson, C. D. (2008). "Language and simulation in conceptual processing," in Symbols, Embodiment, and Meaning, eds M. De Vega, A. M. Glenberg, and A. C. Graesser (Oxford: Oxford University Press), 245-283.

Bergen, B., Lindsay, S., Matlock, T., and Narayanan, S. (2007). Spatial and linguistic aspects of visual imagery in sentence comprehension. Cogn. Sci. 31, 733-764.

Cho, Y. S., and Proctor, R. W. (2002). Influences of hand posture and hand position on compatibility effects for up-down stimuli mapped to left-right responses: evidence for a hand-referent hypothesis. Percept. Psychophys. 64, 1301-1315.

Clark, H. H. (1969). Linguistic processes in deductive reasoning. Psychol. Rev. 76, 387-404.

Clark, H. H. (1973). "Space, time, semantics and the child," in Cognitive Development and the Acquisition of Language, ed. T. E. Moore (New York: Academic Press), 27-63.

Krzeszowski, T. P. (1997). Angels and Devils in Hell: Elements of Axiology in Semantics. Warsaw: Wydawn.

Làdavas, E. (1988). Asymmetries in processing horizontal and vertical dimensions. Mem. Cogn. 16, 377-382.

Lakoff, G., and Johnson, M. (1980). Metaphors We Live By. Chicago: University of Chicago Press.

Louwerse, M. M. (in press). Symbol interdependency in symbolic and embodied cognition. Top. Cogn. Sci. doi: 10.1111/j.1756-8765.2010.01106.x. [Epub ahead of print].

Louwerse, M. M., and Jeuniaux, P. (2010). The linguistic and embodied nature of conceptual processing. Cognition 114, 96-104.

Meier, B. P., Hauser, D. J., Robinson, M. D., Friesen, C. K., and Schjeldahl, K. (2007). What's "up" with god? Vertical space as a representation of the divine. J. Pers. Soc. Psychol. 93, 699-710.
Olson, G. M., and Laxar, K. (1973). Asymmetries in processing the terms "right" and "left." J. Exp. Psychol. 100, 284-290.

Pecher, D., Van Dantzig, S., Boot, I., Zanolie, K., and Huber, D. E. (2010). Congruency between word position and meaning is caused by task-induced spatial attention. Front. Psychol. 1:30. doi: 10.3389/ fpsyg.2010.00030

Proctor, R. W., and Cho, Y. S. (2006). Polarity correspondence: A general principle for performance of speeded binary classification tasks. Psychol. Bull. 132, 416-442.

Richardson, D. C., Spivey, M. J., Barsalou, L. W., and McRae, K. (2003). Spatial representations activated during real-time comprehension of verbs. $\operatorname{Cog} n$. Sci. $27,767-780$.

Schubert, T. W. (2005). Your highness: vertical positions as perceptual symbols of power. J. Pers. Soc. Psychol. $89,1-21$.

Seymour, P. H. K. (1974). Asymmetries in judgments of verticality. J. Exp. Psychol. 102, 447-455.

Van Dantzig, S. (2009). Mind the body: grounding conceptual knowledge in perception and action. Unpublished Doctoral Dissertation, Erasmus University, Rotterdam, The Netherlands.

Weeks, D. J., and Proctor, R. W. (1990). Salient-features coding in the translation between orthogonal stimulus-response dimensions. J. Exp. Psychol. Gen. 119, 355-366.

Received: 14 December 2010; accepted: 01 February 2011; published online: 10 February 2011

Citation: Lakens D (2011) High skies and oceans deep: polarity benefits or mental simulation? Front. Psychology 2:21. doi: $10.3389 /$ fpsyg.2011.00021

This article was submitted to Frontiers in Cognition, a specialty of Frontiers in Psychology.

Copyright (C) 2011 Lakens. This is an open-access article subject to an exclusive license agreement between the authors and Frontiers Media SA, which permits unrestricted use, distribution, and reproduction in any medium, provided the original authors and source are credited. 